\title{
Assessing the efficiency of municipal expenditures regarding environmental protection
}

\author{
J. Soukopova \& E. Bakos \\ Department of Public Economics, \\ Faculty of Economics and Administration, Masaryk University, \\ Czech Republic
}

\begin{abstract}
This article deals with the efficiency of the usual municipal expenditures on environmental protection and suggests a methodology for assessing this efficiency. Firstly, the paper analyses the concept of efficiency from the view of individual rationality. The authors consider efficiency in the sense of $3 \mathrm{E}$ methodology - economy, efficiency and effectiveness and the methodology of sustainable development - the social, environmental and economic parts of sustainable development, as well as the role of those who make decisions in environmental politics. A proposal of a methodological procedure for assessing municipal expenditure efficiency is presented next. It uses multi-criteria assessment, where a dominant criterion of performance is $\mathrm{C} / \mathrm{E}$. This procedure is applied to a file of environmental expenditure data from the representative sample of municipalities in selected areas of environmental protection that were used in a project of the Ministry of Environment of the Czech Republic $\mathrm{SP} / 4 \mathrm{i1} / 54 / 08$ "Analysis of municipal budgets efficiency in relation to the environmental protection". The data comes from selected municipality budgets and are analyzed for the time range of 2001-2008, because the data has been in electronic form since then.
\end{abstract}

Keywords: efficiency, effectiveness, economy, municipal environmental expenditures, sustainable development. 


\section{Introduction}

The issue of the relation between economic growth and environmental protection has become increasingly important in recent years. In question are also the effects of environmental policy in individual regions and the influence of environmental policy on economic growth and other basic regional economic indicators, such as unemployment, inflation, trade and living standards. The problem of allocation of public expenditures in this field is also related with this; specifically how much, in what way and for what purpose should taxpayers' money be spent in relation to environmental protection. This was the reason for the Ministry of the Environment (MoE) of the Czech Republic funding project $\mathrm{SP} / 4 \mathrm{i1} / 54 / 08$ "Analysis of local budgets and their efficiency in relation to environmental protection". Its main objective is to evaluate the efficiency of public expenditures and other financial instruments in the field of environmental protection with focus also on particular regions and the optimization of the incidence of public subsidies in the field of environmental protection on macroand micro-economical levels. The important part is identification of factors influencing the absorption capacity of individual regions in the Czech Republic and the setting of indicators for the evaluation of their efficiency.

\section{Analysis of environmental public expenditures}

Public expenditures in the field of environmental protection are the important part of total public expenditures and probably even in times of financial crisis their amount will not decrease notably, thanks to the active policy of the European Union and expenditures from its structural funds. Figure 1 shows the progression of public expenditures since 1997.

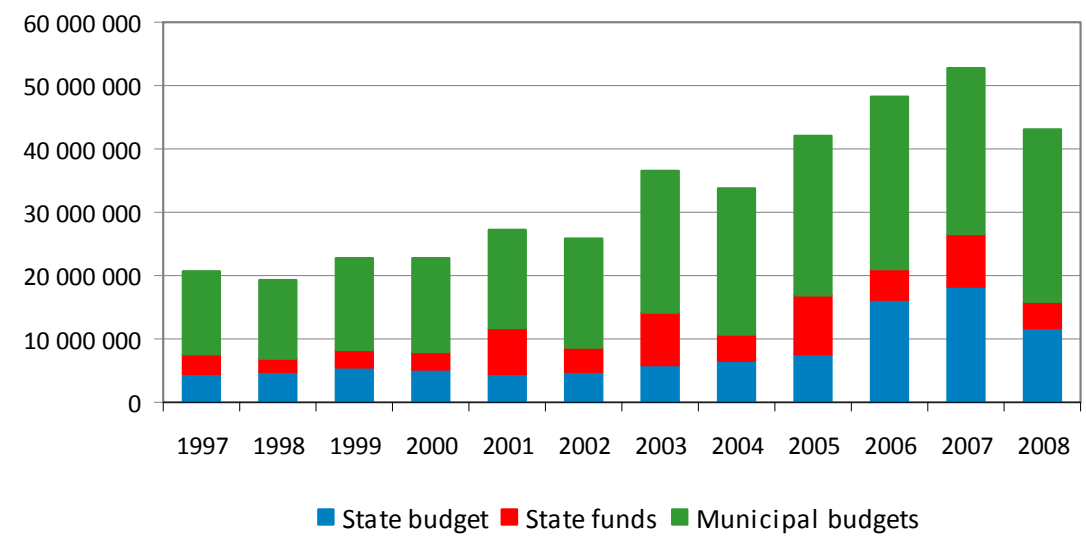

Figure 1: Environmental expenditures of public budgets (in thousands CZK) [11]. 
In Figure 1 we can see that municipal expenditures made throughout the time covered are always more than $50 \%$ of total environmental public expenditures.

Environmental expenditures in the budget structure are divided according to the Classification of Environmental Protection Activities and Expenditure (CEPA 2000), which differentiate the protection of ambient air and climate, wastewater management, waste management, protection and remediation of soil, groundwater and surface water, noise and vibration abatement, protection of biodiversity and landscapes, protection against radiation, research and development and other environmental protection activities [12]. As shown in Figure 2, the largest parts of environmental municipal expenditures are wastewater management expenditures, waste management expenditures and protection of biodiversity landscapes expenditures.

\section{Environmental public expenditures efficiency}

One of the biggest problems of contemporary economic theory is the one of defining and measuring the efficiency, or in other words use, of resources and their transformation into outputs and outcomes. Already in 1957 Farell had asked the question of how to measure efficiency and pointed out [8] its importance for economic policy makers: "it is important to know how far a given industry can be expected to increase its output by simply increasing its efficiency, without absorbing further resources" [4]. There have been several decades of efficiency evaluation and technologies are greatly improved and advanced. However, there still remains a conceptual challenge in relation to public expenditures, given that the problem is also complicated by the fact that outcomes of the public sector are

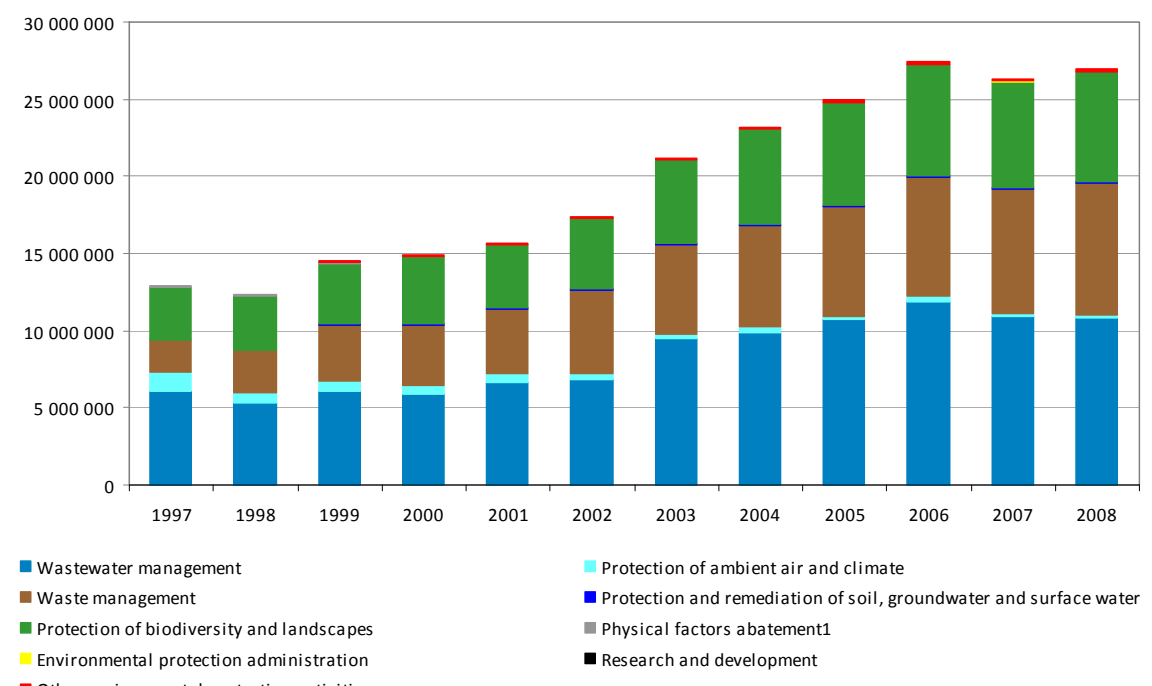

Figure 2: $\quad$ Municipal environmental expenditures according to CEPA 2000 (in thousands CZK) [11]. 
often off-market, lacking relevant data and thus making them unquantifiable, as stated by the collective of authors at the European Commission [8]. It is the very conceptual frame of inputs, outputs and outcomes that these authors are pointing out. They highlight the difference in comprehension concepts of output and outcome. While they see the efficiency in the transformation of inputs to outputs (comparing it to productivity, which they see as a level of product created from input used), which includes also the concept of the production possibilities frontier (in other words the more output we create from a given input or the less input is required for desired output, the more efficient is the activity), they ask for effectiveness in relation between output and outcome, which they perceive as richness or growth in society and which is, besides political decisions, influenced by various other external factors (those identified by member states as key factors related to public expenditures were performance orientation, organizational aspects, human resource management, information technology utilization). The above described problem of expressing differences between concept of inputs, outputs and outcomes and related understanding and measuring of efficiency also related to public expenditures has been investigated by Mandl et al. [8] and many other authors [3, 5-7, 9].

To evaluate the efficiency of public expenditures (environmental), most authors use the methodology of 3E - economy, efficiency and effectiveness, which they perceive from a theoretical basis as follows:

- By economy they understand such use of public expenditures that leads to provision of the given objectives with the least amount of resources spent, while keeping up to the corresponding quality of tasks;

- By efficiency they understand such use of public expenditures that acquires the greatest possible amount, quality and contribution to the given objectives compared to the amount of resources spent in order to fulfil them.

Economy and efficiency are for purposes of quantification and in respect of usage of methods of economic analysis understood as cost efficiency.

- By effectiveness they understand such use of public expenditures that leads to the greatest possible output in respect of the desired outcome, which is a prerequisite for optimal fulfilment of goals set in advance. Therefore, effectiveness means how the produced goods or services (for example waste disposal) fulfil the utility (for example clean municipal environment without waste).

In addition to this classic 3E methodology, the term 'quality' is sometimes used. Quality means such that the use of public expenditures provide an optimal rate of accomplishment of the "right goals" while performing given objectives. It means that it is possible to ask about correctness and appropriateness of given goals in, for example, strategic documents or from the point of the legitimacy of their fulfilment, or the utility set by them. It is important to strongly differentiate between quality and effectiveness, which are sometimes interchanged, for example in the concept of quality, where it comes to optimal fulfilment of goals while carrying out given objectives. In this concept it is not clear enough what process is used to set up goals and to what extent these goals are "objectively" right, or appropriate. Sometimes it is possible to purposefully (in terms of 
purpose) fulfil the goals, but not in optimal ways, meaning not taking into account cost amount. When judging all these criteria (economy, efficiency, effectiveness and quality) we can speak of the economical efficiency of public expenditures. For the complex view we need to add that sometimes we distinguish between the terms technical and allocation efficiency. However, this concept's analysis is beyond the scope of this text. Figure 3 shows the concept of economical efficiency, from which we move out into further analysis and we use it for the construction of a methodology for the evaluation of environmental municipal expenditures.

\section{Methodology of efficiency evaluation}

One of the contemporary problems is how to allocate public expenditures in the field of environment protection more effectively.

When considering efficiency, the methodology is based on a multi-criteria evaluation of efficiency based on three basic pillars of sustainable development. When we designed the methodology we started from the assessment of efficiency in terms of social, environmental and economical points of view (see Figure 4).

\subsection{Social aspect of evaluation}

The social criteria of evaluation take the social aspect of existing expenditure into account. The complex criterion for evaluating efficiency from the social point of view $K_{S}$ could be constructed as follows:

$$
K_{S}=\sum_{i=1}^{n} w_{i} k_{S i}
$$

where $k_{S i}$ is the social efficiency criterion (in percent),

$n \quad$ is the number of criteria,

$w_{i} \quad$ is the weight of criterion No. $i$, and $\sum_{i=1}^{n} w_{i}=1$.

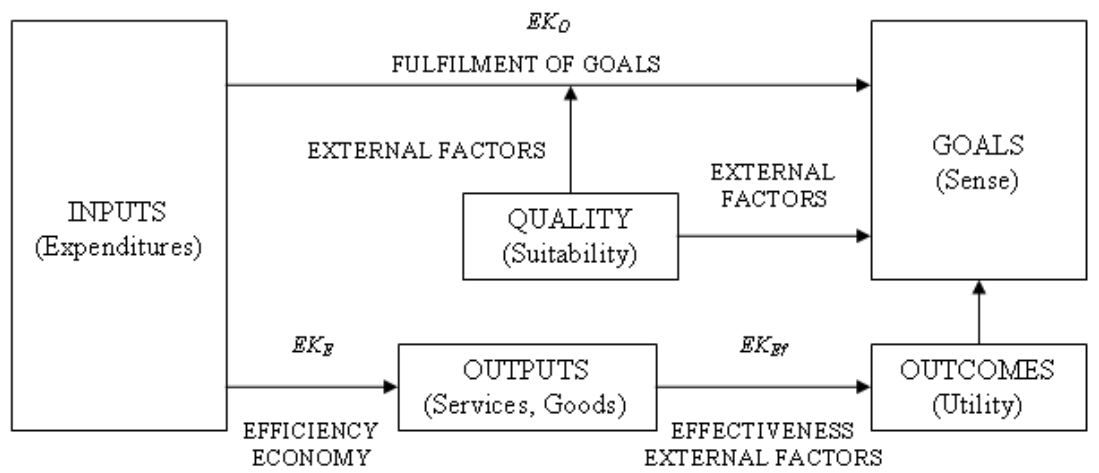

Figure 3: Conceptual conception of efficiency of public expenditures. 


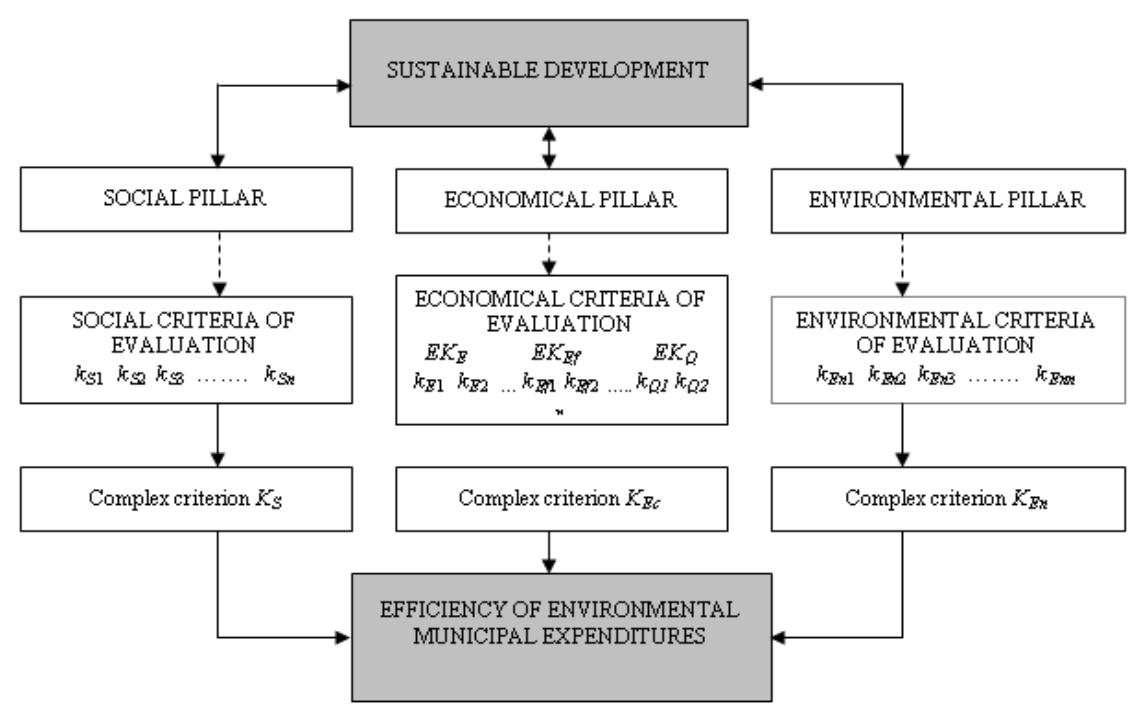

Figure 4: Scheme of environmental public expenditure efficiency evaluation.

If it holds that $0 \leq K_{S} \leq 1$ and if $K_{S}=0$ then the expenditure is absolutely inefficient.

\section{Example 1}

When it comes to municipal waste management expenditures, suitable criteria for social efficiency evaluation of given expenditures could be the following:

$k_{S 1} \quad$ Willingness to sort municipal waste (in percent)

$k_{S 2} \quad$ Employment - Influence on employment (is the given service carried out by a local company or an external one, and so on) (in percent)

$k_{S 3} \quad$ Living standard of citizens - has the expenditure had a positive impact on the living standard of citizens in the municipality (in percent)

When evaluating municipal waste management expenditures in Brno, experts gave these weights to the given criteria $w_{1}=0.4 \quad w_{2}=0.3 \quad w_{3}=0.3$ and the following values:
Criterion
$k_{S 1}$
$k_{S 2}$
$k_{S 3}$
Criterion value
0.58
0.85
0.86

Then, $K_{S}=0.748$.

\subsection{Economical aspect of evaluation}

The economical criteria of evaluation are based on the concept of efficiency explained above and include the economical evaluation of efficiency and economy $E K_{E}$, economical effectiveness $E K_{E f}$ and economical quality $E K_{Q}$, so:

$$
K_{E}=E K_{E}+E K_{E f}+E K_{Q} \text {, }
$$


where $K_{E} \quad$ is the complex criterion of economical efficiency evaluation,

$E K_{E}$ is the complex criterion of economical efficiency and economy evaluation (cost efficiency evaluation),

$E K_{E f}$ is the complex criterion of economical effectiveness evaluation,

$E K_{Q}$ is the complex criterion of economical quality evaluation (quality of environmental goals).

A more detailed explanation of the methodology of evaluation according to the given complex criteria follows.

\subsubsection{Economy and efficiency evaluation $-E K_{E}$}

The most commonly used methods for evaluating the efficiency of public expenditures (capital and current) are Cost-minimization Analysis, Costeffectiveness Analysis (CEA), Cost-utility Analysis (CUA) and Cost-benefit Analysis (CBA). These methods are suitable for the evaluation of the efficiency of public expenditures for environmental protection. The only exception is Costminimization Analysis, which only compares amount of costs (expenditures) in certain investment; therefore we will not consider it further for the evaluation of environmental public budget expenditures. The efficiency evaluation of current expenditures of public budgets, however, encounters several limitations. This is because current expenditures usually consist of expenditures for public services - services of common interest. This makes it quite difficult to evaluate expenses using CBA or CUA. In the case of CBA it is difficult to estimate the benefit of these services in terms of money and as for CUA, the situation is even more complicated because there is no suitable methodology for environmental expenditures (however it exists for healthcare and others) [1]. Therefore, the most exact method appears to be CEA [2]. When it comes to the evaluation of efficiency, and for the evaluation of $\mathrm{C} / \mathrm{E}$, choosing efficiency indicator $\mathrm{E}$ as a complex criterion created with the help of a multi-criterial analysis depending on the factors influencing expenditures on a given environmental service appears to be the best option.

Let $K_{E}$ be a set of criteria for the evaluation of the quality of environmental public budget expenditures, where $K_{E}=\left(k_{E 1}, k_{E 1}, \ldots, k_{E n}\right)$, so

$$
E=f\left(k_{E 1}, k_{E 2}, \ldots . ., k_{E n}\right),
$$

where $k_{E i}$ is the criterion of cost efficiency and economy evaluation,

$n \quad$ is the number of outputs for a given environmental expenditure.

Then the cost efficiency of a given expenditure could be expressed as follows:

$$
C E A=\frac{C}{E} \geq 0 \rightarrow \min
$$

where $C$ are environmental expenditures,

$E \quad$ is the indicator of the cost efficiency evaluation.

If $C E A \leq 1$, then the expenditure is efficient, if $C E A>1$, then the expenditure is inefficient. Because the criterion is minimizing, it needs to be transformed into a maximizing one. Therefore for the construction of the $E K_{E}$ criterion we will use the following formula: 


$$
E K_{E}=\frac{1}{C E A}=\frac{E}{C} \geq 0,
$$

where if $E K_{E}>1$, then the expenditure is efficient and $E K_{E} \rightarrow \max$.

\section{Example 2}

In 2008 the city of Brno spent in the area of waste management 189,947.87 thousand CZK for municipal waste collection and 176,511.6 thousand CZK for the use and disposal of municipal waste, i.e. the total cost of waste management is $C=366,459.47$ thousand CZK. The same year the city of Brno was producing $Q=118,662.87$ tons of municipal waste $\left(k_{E 1}\right)$, the average price for waste treatment was $p=1,500 C Z K$ (incinerator) $\left(k_{E 2}\right)$, the average distance to processing facilities was $v=20$ kilometres $\left(k_{E 3}\right)$, and the average size of a mean of transportation for waste was $25 t\left(k_{E 4}\right)$, the average rate for transport was 45 $C Z K / t\left(k_{E 5}\right)$ and the average rate for handling was $30 \mathrm{CZK} / \mathrm{t}\left(k_{E 6}\right)$. Then, in the case of the collection of municipal waste being the criterion, the waste amount, price of waste manipulation, price of waste transport, means of transportation capacity and distance to processing facilities are used to calculate the costs of collection, as follows:

$$
\begin{gathered}
E=E_{1}+E_{2}, \\
E_{1}=N_{S}=2 * v * s_{d} * \frac{Q}{k_{d}} * m, \quad E_{2}=Q * p,
\end{gathered}
$$

where $v \quad$ is the distance from the facility (landfill, incinerator) $[\mathrm{km}]-\left(k_{E 3}\right)$

$s_{d} \quad$ is the rate for transportation $[\mathrm{CZK} / \mathrm{km}]$, considered $45 \mathrm{CZK} / \mathrm{km}$ $\left(k_{E 5}\right)$

$Q \quad$ is the amount of waste [t] $\left(k_{E I}\right)$

$k_{d} \quad$ is the capacity of the means of transport for waste [t], considered to be a maximal capacity of $25 t$. $\left(k_{E 4}\right)$

$m$ is the price for manipulation $[\mathrm{CZK} / \mathrm{t}]$

Then, $E_{1}=192,233.85 C Z K, E_{2}=177,994.305 C Z K$ and $E=370,228.155$. It follows: $E K_{E}=1.01$.

\subsubsection{Evaluation of the effectiveness $-E K_{E f}$}

Let $K_{E f}$ be a set of criteria for the evaluation of effectiveness of environmental municipal expenditures, where $K_{E f}=\left(k_{E f 1}, k_{E f 1}, \ldots, k_{E f \mathrm{n}}\right)$, then

$$
E K_{E f}=\sum_{i=1}^{n} w_{i} k_{E f i}
$$

Where $k_{E f i}$ is the criterion determining the results of a given expenditurepercentual fulfilment of goal No. $i$ (criterion acquires values $0-1$ ),

$n$ is the amount of outcomes (goals) for given environmental expenditure,

$w_{i} \quad$ is the weight of the $i$-numbered criterion, which fulfils $\sum_{i=1}^{n} w_{i}=1$.

It holds that $0 \leq E K_{E f} \leq 1 \rightarrow \max$. 


\section{Example 3}

The City of Brno is planning in its waste management area the following objectives and performance criteria of expenditure effectiveness.

1. Increase material utilization of municipal waste to $50 \%$ by 2010 compared to $2000-k_{\text {Enf } 1 \text {; }}$

2. Material utilization of municipal waste in relation to the whole Czech Republic (ensure the collection, subsequent use or disposal of controlled hazardous components of municipal waste (50\% in 2005 and $75 \%$ in 2010)) $-k_{E f 2}$;

3. Ensure recycling of construction and demolition waste (utilize 50\% of the weight of emerging construction and demolition waste before 31. 12. 2005 and $75 \%$ before 2012$)-k_{E f 3}$;

4. Prefer incineration of mixed municipal waste with energy recovery prior to landfill storage $-k_{E f}$;

5. Reduce the weight ratio of landfilled waste with the perspective of a further reduction of $20 \%$ in 2010 compared with $2000-k_{E f}$;

6. Decrease the ratio of landfilled waste with energetic utilization potential (35\% in 2010) - $k_{E f 6}$;

7. Decrease the ratio of landfilled biodegradable municipal waste (75\% of what the production was from 1995 to 2010) $-k_{E f}$;

8. Increase the utilization of waste through recycling up to $55 \%$ in $2012-k_{E f 8}$.

For simplicity, all the criteria were assigned the same weight, $w_{i}=0.125$. The expert panel gave each criterion the following values:

$\begin{array}{lcccccccc}\text { Criterion } & k_{E f 1} & k_{E f 2} & k_{E f 3} & k_{E f 4} & k_{E f 5} & k_{E f 6} & k_{E f 7} & k_{E f 8} \\ \text { Criterion value } & 0.95 & 1 & 0.86 & 1 & 0.85 & 0.95 & 0.65 & 1\end{array}$

Therefore, $E K_{E f}=0.9075$.

\subsubsection{Evaluation of the quality $-E K_{Q}$.}

Let $E K_{Q}$ be a set of criteria for the evaluation of the quality of environmental public budget expenditures, where $E K_{Q}=\left(k_{Q 1}, k_{Q 1}, \ldots, k_{Q \mathrm{n}}\right)$, then

$$
E K_{Q}=\sum_{i=1}^{n} w_{i} k_{Q i}
$$

Where $k_{Q i} \quad$ is the criterion determining quality - quality of a given goal - in connection with strategic documents of region or state (in percent) (criterion acquires values $0-1$ ),

$n$ is the amount of outcomes (goals) for given environmental expenditure,

$w_{i} \quad$ is the standardized weight of criterion No. $i$.

Example 4

The South Moravian Region has in its strategic document - Waste Management Plan (WMP) - 25 goals related to waste management. The city of Brno has given in its waste management eight goals, which are all included in the WMP South Moravian region; therefore, these criteria take the value of 1 (100\% associated with the strategic documents). Considering the evaluation of quality of 
expenditures, it is possible to use the criteria in Example 3 and build EK , when $E K_{Q}=1$.

For the city of Brno the complex criterion for the evaluation of economical efficiency comes out as follows:

$$
K_{E}=E K_{E}+E K_{E f}+E K_{Q}=0.9898+0.9075+1=2.8973
$$

\subsection{Environmental aspect of evaluation}

Environmental criteria of evaluation are obtained from indicators of sustainable development in the selected field of environmental protection. The complex criterion of the evaluation of efficiency could be from the view of environmental $K_{E n}$, constructed as follows:

$$
K_{E n}=\sum_{i=1}^{n} w_{i} k_{E n i}
$$

Where $k_{E n i}$ is the criterion of environmental efficiency, $k_{E n i} \rightarrow \max$

$n \quad$ is the amount of criteria,

$w_{i} \quad$ is the standardized weight of criterion No. $i$.

It holds that if $K_{E n} \geq 0$. If $K_{E n}=0$, the expenditure is fully inefficient.

Example 5

Considering waste management expenditures, the criteria for the evaluation of environmental efficiency could be the following, which are maximizing.

$k_{\text {En1 }} \quad$ Amount of municipal solid waste per capita in comparison with the Czech national average (national average proportion of the municipality value);

$k_{E n 2} \quad$ Weight ratio of going to landfills, compared with the Czech average (ratio of Czech average to the actual municipality value);

$k_{E n 3} \quad$ Waste management expenditures per capita compared to the Czech average (ratio of Czech average to the actual municipality value);

$k_{\text {En4 }}$ Ratio of biodegradable municipal solid waste going to landfills, compared with the Czech average (ratio of Czech average to the actual municipality value);

$k_{E n 5} \quad$ Utilization of waste through recycling compared with the Czech average (ratio of Czech average to the actual municipality value).

Experts assigned these criteria by similar weight of $w_{i}=0.2$. The expert panel attributed to each criterion the following values:

$\begin{array}{lccccc}\text { Criterion } & k_{E n 1} & k_{E n 2} & k_{E n 3} & k_{E n 4} & k_{E n 5} \\ \text { Criterion value } & 1.099 & 1.541 & 0.823 & 1.125 & 1.02\end{array}$

Then, $K_{E n}=1.122$

\subsection{Summary of the methodology}

The sequence of our suggested methodology for the evaluation of public budget expenditures for environmental protection could be shown in several phases and steps:

1. Phase - evaluation of efficiency from the social view, $0 \leq K_{S} \leq 1 \rightarrow \max$; 
2. Phase - the evaluation of the economical efficiency:

- Step 1 - the evaluation of efficiency and economy of expenditures (whether the given goals are being fulfilled with minimal costs, or if the environmental benefits with given costs are maximized). $E K_{E}>1 \rightarrow$ $\max$;

- $\quad$ Step 2 - the evaluation of effectiveness (how municipal environmental expenditure ensures the setting of goals). $0 \leq E K_{E f} \leq 1 \rightarrow \max$;

- $\quad$ Step 3 - the evaluation of quality (quality of goals is a crucial problem of expenditures, which is why we also evaluate it). $0 \leq E K_{Q} \leq 1 \rightarrow \max$

3. Phase - the evaluation of efficiency from an environmental view. $K_{E n} \geq 0 \rightarrow \max$.

\section{Example 6}

If we apply the methodology to the waste management expenditures of Brno in 2008, then we can use Examples 1-5 and the evaluation of efficiency according to our methodology would be as follows:

$\begin{array}{cccccc}\text { Phase 1 } & & \text { Phase 2 } & & \text { Phase 3 } & \text { Overall evaluation } \\ K_{S} & E K_{E} & E K_{E f} & E K_{Q} & K_{E n} & \\ 0.905 & 1.01 & 0.9075 & 1 & 1.122 & 4.9895\end{array}$

When it is compared with the average of municipalities of the South-Moravian region, where the overall evaluation value is 4.8254, we can say that the efficiency of Brno's waste management expenditures is very good.

\section{Conclusion}

This paper is one of the results of the project of the Ministry of Environment (MoE) of the Czech Republic SP/4i1/54/08 "Analysis of municipal budgets efficiency in relation to the environmental protection", where we identified that the efficiency evaluation of municipal environmental expenditures is an extraordinary difficult task. Just to determine economy and efficiency from a quantifying viewpoint with methods of economical analysis is not simple. The greatest problem is to estimate the benefits of public services in terms of money. We discussed why the most appropriate way seems to be the Cost-effectiveness Analysis and its application as a part of a multi-criteria analysis, depending on factors influencing expenditures on a given environmental service. Determination of all these factors, as shown in the examples in the paper, is a prerequisite for establishing an indicator of efficiency.

It is much more complicated when determining efficiency and quality of public expenditures. This opens several questions and tasks, which we are solving in the project No. SP/4i1/54/08 of MoE. What is the extent to which outputs are active in relation to the outcomes? How should one determine the success of the objectives? Are the goals set "correctly"? How should one identify that? How should one assess the quality of the given objectives? Are citizens' 
views and opinions relevant? Or it can be assumed using previously given objectives in the national and regional documents? For simplicity, we just assessed the compliance of the objectives set at the local level with the objectives set in national and regional strategic documents. We believe that this is one of the ways to assess the efficiency of public spending on environmental protection. The set of objectives and targets in the strategic documents of the Czech Republic and its regions, in our view, in itself reflects practical effects for improving the environment in the region and this leads to an increase in the overall living standard of the population and sustainable development.

At the same time we realize that the described problem in the project No. $\mathrm{SP} / 4 \mathrm{i} 1 / 54 / 08$ of the MoE is much more complicated in practice, because the amount of public spending is influenced by a variety of external factors, such as orientation to performance, organizational aspects, human resources, the use of information technology, political decisions, interest groups, etc. Some of these factors cannot be quantified, they can only be described. International organizations already recognize the complexity of size and efficiency of public expenditures and their management to protect the environment and thus there have been formulated advices referred to as "good practices" [10] for the management of public expenditure with regard to environmental protection. These "good practices", however, are more general and refer to a broader access to public spending than the presented methodology for the assessment of the public spending efficiency of local budgets for environmental protection in the paper.

\section{Acknowledgement}

This paper is supported by the project of the Ministry of Environment of the Czech Republic SP/4i1/54/08 "Analysis of municipal budgets efficiency in relation to the environmental protection".

\section{References}

[1] Boardman, A., E. Cost-benefit analysis: concepts and practice. 2nd ed. Upper Saddle River: Prentice Hall, 2001. 526 p., ISBN 0-13-087178-8

[2] Levin, H., M., McEwan, P., J. Cost-effectiveness analysis: Methods and applications. 2nd ed. Sage Publications, Inc; 2000, 308 p., ISBN 0-76191934-1

[3] Ochrana, F. Veřejný sektor a efektivní rozhodování. 1. vyd. Praha: Management Press. 246 p. ISBN 80-7261-018-X, 2001

[4] Farrell, J. The Measurement of productive efficiency, Journal of the Royal Statistical Society, Part III Vol.120, pp.11ff, 1957

[5] Pavel, J., Slavíková L., Jílková J. Economics Instrument of Environmental policy: Costly Taxes and Low Effectiveness, Journal of Economics, vol. 57, No. 2, pp 132-144. ISSN 0013-3035, 2009 
[6] Robinson, M. Output-Purchase Funding and Budgeting Systems in the Public Sector. Public Budgeting \& Systems, vol. 22, pp. 17-33. ISSN 10963367, 2002

[7] Allen, R., Tommasi, D. (eds) Managing Public Expenditure: A reference book for transition countries, Paris, OECD, 2001

[8] Mandl, U., Dierx, A., Ilkowitz, F. The effectiveness and efficiency of public spending, European Commission, Economic paper 301, 2008

[9] Nath, N., Van Peursem, K., Lowe, A. Public Sector Performance Auditing: Emergence, Purpose and Meaning. Working Paper Series - Department of Accounting, The University of Waikato, 2005. no. 81, 40 p. ISSN 11737182

[10] Good practices of public environmental expenditure management in transition economies, Fifth Ministerial Conference, Environment for Europe, Kiev, Ukraine, 21-23 May 2003 www.oecd.org/dataoecd/51/59/ 34595093.pdf

[11] Information system ARIS http://wwwinfo.mfcr.cz/aris/

[12] EUROSTAT http://ec.europa.eu/eurostat/ramon/nomenclatures/index.cfm? TargetUrl=LST_NOM_DTL\&StrNom $=$ CEPA_2000\&StrLanguageCode $=\mathrm{E}$ N\&IntPcKey $=\overline{\& S}$ trLayoutCode $=$ HIERARCHIC $\&$ CFID $=12332028 \&$ CFTO $\mathrm{KEN}=344 \mathrm{c} 95$ f81 e92cf39-AD596786-B0DD-5AA5-B6EB07E23EB60B0\& jsessionid=f90093be44df7a11125a 